\title{
Reactor may switch to low-grade uranium
}

[MUNICH] Germany's controversial new FRMII research reactor, being built to run on weapons-grade highly enriched uranium (HEU), could be converted to use low enriched uranium (LEU) by 2008 , says a new report.

The DM810 million (US\$430 million) 20 megawatt neutron source would not need to be completely rebuilt, and the conversion would not damage relevant scientific research, according to the expert committee's report, published last week.

The Technical University of Munich (TUM) has continued building the reactor, currently scheduled for operation by 2001, despite protests that the use of HEU in research reactors breaks international proliferation agreements. The new German Social Democrat and Green coalition government committed itself to investigate the possibility of converting the reactor in its coalition agreement.

The report outlines three possibilities for the FRMII, but makes no recommendation. The first - immediate conversion to the use of existing LEU fuel, along with a power upgrade to $32 \mathrm{MW}$ to maintain neutron flow densityis certain to be ruled out on cost grounds.

The second option - immediate conversion to the use of LEU without increasing the reactor's power - would delay its operation by at least three years. The expert committee considers this a "reasonable" period, but it would also result in a 20-30 per cent reduction of the neutron flow density. The university says the costs of this option would still be very high, at about DM300 million.

The third option - building and operating the reactor as planned and converting it to use a specially developed low or medium enriched fuel element, geared to FRMII's design, when it becomes available - would cost only about DM12 million, says the report. Moreover, the reduction of the neutron flow density would be only seven per cent, which "would cause no considerable limitation of the scientific use of the FRMII".

The United States and France have industrial research programmes to develop suitable LEU fuel for research reactors. The report concludes that if Germany and the university are serious about converting FRMII, they should take part in this research.

But the expert committee estimates that such fuel would take around seven years to develop. During this time, proliferation problems related to the interim use of HEU must be taken seriously. It warns that continued use of HEU could weaken international efforts to prevent the fuel being used for weapons, and says that "less trustworthy" countries could cite FRMII to justify their own HEU reactor projects.

The university has welcomed the "precise

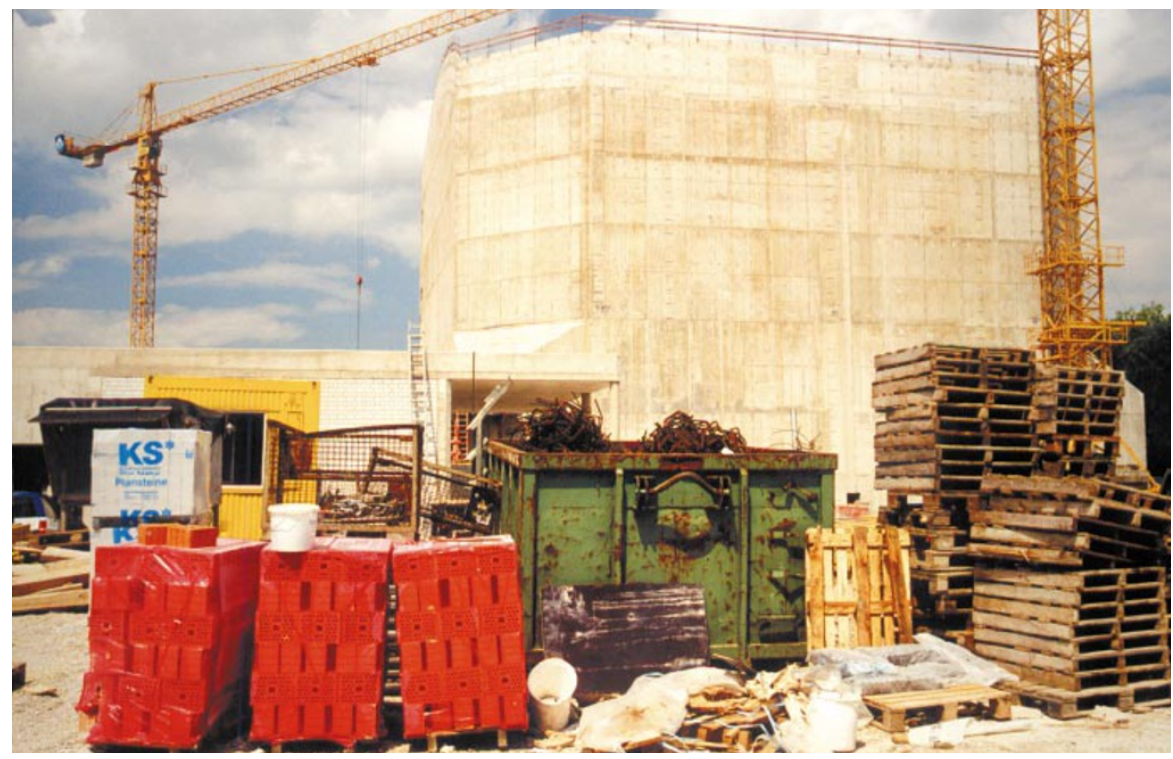

Building work: the FRMII reactor is currently being built to use weapons-grade uranium.

technical survey" which the report provides, but rejects its political statements. "Addressing the issue of proliferation was not among the commission's tasks", says Gert von Hassel, spokesman for the FRMII project.

But Hans-Josef Fell, the Green parliamentary group's spokesman on research, says the university's view of FRMII as a purely scientific matter is "politically unacceptable".

The Greens are aware of the "central importance" of neutron research, says Fell, but the immediate conversion of the reactor is a high political priority among party leaders. "We must not be ignored once again by our SPD coalition partner," he says, referring to the Greens' previous concessions to the SPD over nuclear power policies (see Nature 397, 189; 1999).

But conversion of the reactor seems likely to be delayed. The university, supported by the Bavarian government, has said it would agree to a future conversion, but for now insists on building and operating the neutron source according to the initial design.

The options will be discussed between federal government and the Bavarian state government. A decision is expected within the next six months.

QuirinSchiermeier

\section{European Union tightens GMO regulations}

[PARIS] Regulations on the environmental release of genetically modified organisms (GMOs) were tightened last week by ministers of the 15 member states of the European Union. Meeting in Luxembourg, they voted that GMOs should be given only provisional marketing approvals for ten years and not unlimited authorizations as at present. France, Ireland and Italy abstained.

Under the agreement, initial approvals would be considered only for releases "meeting certain safety criteria where sufficient experience exists". They would also require an environmental risk assessment, be subject to "extensive consultation" with scientists and the public, and meet a series of compulsory monitoring requirements. Products would also need to be labelled clearly as containing GMOs.

A moratorium on new approvals, proposed by Greece and supported by France, was rejected. The new regulations are unlikely to come into force for at least two years, as they require the approval of the European parliament. This may therefore amount to a de facto moratorium.

Paul Muys, a spokesman for EuropaBio, an association that represents the European biotechnology industry, argues that the fact that the European Union has agreed on a common position is progress. At the same time, he deplores what he sees as unnecessary new layers of regulation for a technology that poses no new risks and is already tightly regulated.

A requirement to renew approvals after ten years is unnecessary, argues Muys, as existing regulations allow for products to be withdrawn if evidence of risks emerges. $\mathrm{He}$ adds that a non-binding statement issued after the meeting by France, Denmark,Italy, Greece and Luxembourg, calling for a freeze on approvals until the new regulations come into force, confirms industry's worst fear: that a moratorium on GMOs is now in place in Europe. Heather McCabe \& Declan Butler 